Research Article

\title{
Construction Project Safety Performance Management Using Analytic Network Process (ANP) as a Multicriteria Decision-Making (MCDM) Tool
}

\author{
Murat Gunduz $\mathbb{D}$ and Basil K. Khader \\ Dept. of Civil Engineering, Qatar University, Po Box: 2713, Doha, Qatar \\ Correspondence should be addressed to Murat Gunduz; mgunduz@qu.edu.qa
}

Received 2 December 2019; Revised 11 January 2020; Accepted 21 January 2020; Published 25 February 2020

Academic Editor: Carmen De Maio

Copyright ( 2020 Murat Gunduz and Basil K. Khader. This is an open access article distributed under the Creative Commons Attribution License, which permits unrestricted use, distribution, and reproduction in any medium, provided the original work is properly cited.

\begin{abstract}
The paper addresses the context in which the construction industry is considered risky, as the intense labor and machine environment interacts with acceleration and overlapping activities. This situation results in accidents and fatalities. A high number of accidents and fatalities leads to additional costs and delays, detrimental to all stakeholders. Hazard identification and quantification of their impacts on building safety are crucial for planning. Classifying security risks is a complex process, and risks are interconnected. There is a gap in the literature to study the interconnections of these hazards along with the frequency of occurrences. To bridge this gap, the frequency-adjusted importance index and the ANP (Analytical Networking Process) tool were used to capture the 14 interconnections and their frequencies based on the results of a survey distributed to 106 construction professionals. The main contribution of this work to existing knowledge is to identify and prioritize potential risks in the construction sector, considering their interconnections and their level of occurrence frequency. This is the first study in the literature to combine the frequency-adjusted importance index and the ANP tool, both integrated. The results from the importance index was used as the base for pairwise comparison for the ANP model. Based on the results from the model, recommendations to industry professionals are provided and presented.
\end{abstract}

\section{Introduction}

Construction industry is one of the biggest industries worldwide. Deplorable safety management practices are damaging the reputation of the construction sector [1]. Due to the increasing complexity of construction projects, the construction industry is acknowledged as having inherent risks with high levels of change and uncertainty [2]. Many workers and equipment interact together to deliver the final project on time. This interaction would mostly result in accidents. Safety performance monitoring should be performed by all stakeholders to avoid injuries and fatalities in the construction sites.

The first step in evaluating the safety performance of a construction site is to identify the hazards, evaluate their priorities and effect, and take adequate measures to avoid such hazards. Due to the dangers of the construction industry, leading and lagging safety indicators have been developed to measure safety performance and prevent injury [3]. The application of BIM is currently experiencing rapid growth in construction operations and planning and management, as well as in safety management [4]. New technologies are also used to identify hazards such as BIM (Building Information Modeling) [5]. However, evaluating the priorities of the hazards is a complex issue as many of these hazards are interrelated to each other. Traditional risk analysis methods are not efficient to analyze nonlinear or complex systems such as construction sites [6]. There is a gap in the literature to study the interconnections of these hazards along with their frequency of occurrences. To cover this gap, frequency-adjusted importance index and ANP (Analytic Network Process) tool were jointly utilized to capture the interconnections and their frequencies based on the results from a survey distributed to construction 
professionals. The main contribution of this paper to the existing knowledge is to identify and prioritize potential hazards in the construction sector by considering their interconnections along with their frequency level of occurrences. Although very few researchers used ANP to study construction safety hazards [7-9], they failed to address the frequency component. This is the first study in the literature to introduce frequency component to the ANP tool for realistic capturing of hazard rankings.

After literature review, 42 hazards in 14 categories were identified. These were presented in a survey and distributed online to the construction industry experts. 106 responses were received, analyzed, and ranked using frequency-adjusted importance index and ANP. The results from frequency-adjusted importance index were used as the base for pairwise comparison for the ANP model. The ANP tool reflected the interdependencies between the safety hazards. With the help of ANP, the hazards are linked together in an analytic network to reach a robust model and outcome. The ranked hazards are presented and proper recommendations were made to industry professionals based on the research outputs.

\section{Literature Review}

There is a growing body of the literature on assessing perceptions of safety climate [10]. Construction sites are known for its complex environments where many unsafe acts and/or unsafe conditions exist [6].

Identifying hazards was performed in many studies such as [11-18]. Gunduz et al. [19] conducted an extensive literature review to identify 168 observable variables in 16 latent dimensions that affect safety. The study then proposed a multidimensional safety performance model utilizing structural equation modeling (SEM) analysis. Analytic hierarchy process (AHP) then was used to assess the severity of each. On the other hand, Esmaeili et al.[20] adopted a preconstruction safety management in which they have identified 22 fundamental attributes with highest impact on safety to predict the safety outcome.

Traditional risk analysis methods are not efficient to analyze nonlinear or complex systems such as construction sites [6]. Traditional risk analysis methods are not efficient to analyze nonlinear or complex systems such as construction sites [6].

Few studies in the literature adopted the use of ANP to rank hazards. Yang et al. [8] assessed metro construction safety risk by the use of ANP-grey clustering method. Zhou et al. [9] assessed high-risk hydropower-construction project work system hazards by the analytic network process (ANP) and decision-making trial and evaluation laboratory (DEMATEL). High-rise construction safety culture among job positions with Fuzzy ANP and Fuzzy Decision Trail and Evaluation Laboratory and methods was studied by [7]. The past studies usually study one type of construction without considering their frequency of occurrence on the construction site. There is a gap in the literature to study the interconnections of safety hazards along with the consideration of their frequency of occurrences. This study covers this gap in the literature by considering ANP modeling and the frequency of safety hazards together. With the help of ANP, the hazards are linked together in an analytic network to reach a robust model and outcome. In this study, an extensive literature review on topics related to safety hazards in construction projects was conducted. A draft checklist of 42 hazards in 14 categories (site planning and housekeeping; management involvement; handling, storage, and use of materials; welding and cutting; concrete and concrete framework; crane and lifting equipment; electrical equipment; hand and power tools and machinery; working at height and protection against falling; personal protective equipment; traffic and transportation control; scaffolding and ladders; fire prevention; excavation, trenching, and shoring) were collected. Table 1 presents the top forty-two hazards utilized in the study with their corresponding references. Based on the identified safety hazards, a questionnaire was prepared and distributed among the construction professionals. The questionnaire helped identify the most significant safety hazards in the construction industry.

Next sections will introduce the methodology on frequency-adjusted importance index, ANP, and the data analysis parts.

\section{Methodology}

This study gathered a list of 42 safety hazards from the literature review. A survey approach was adopted as means of collecting data for the data analysis. The survey aimed to investigate perceptions of the respondents on safety hazards attributes in the construction industry. A ranking analysis was applied between respondents based on their organization type, job designation, industry type, total construction experience, and size of their companies. The respondents were requested to evaluate the attributes based on a (1-9) scale for the importance and frequency levels of the factors. The (1-9) scale is depicted in Figure 1. The survey was sent to construction professionals that play key roles in the construction industry worldwide.

A total number of 106 completed surveys was received from the respondents worldwide. Frequency-adjusted importance index and ANP analysis were applied on the collected data. Ranked attributes were interpreted based on the statistical analyses performed. Finally, recommendations to industry professionals were carried based on the outcomes of the data analysis.

\section{Data Characteristics}

An online website tool (SurveyMonkey) was employed in developing, distributing the questionnaire, and collecting responses. Moreover, hardcopies were also distributed to authors' networks. The motivation of the respondents was to receive the outcome of this study after its completion. The main results came from international construction companied based in Qatar, the USA, Japan, Turkey, and Jordan. Respondents are from different companies with different functions, departments, and projects/project types. 
TABle1: The top 42 hazards from the literature review and their relevant references.

\begin{tabular}{|c|c|c|}
\hline Code & Description & References \\
\hline $\begin{array}{l}\mathrm{C} 1 \\
\mathrm{C} 1 \mathrm{H} 1 \\
\mathrm{C} 1 \mathrm{H} 2 \\
\mathrm{C} 1 \mathrm{H} 3\end{array}$ & $\begin{array}{c}\text { Site planning and housekeeping } \\
\text { Insufficient working spaces/wrong site layout/no access/no lights } \\
\text { No housekeeping (scattered garbage and material, dusts, excessive noise, vibration, etc.) } \\
\text { Insufficient food, drinking water, toilets, rest shelters, and medical facilities }\end{array}$ & {$[20-26]$} \\
\hline $\begin{array}{l}\mathrm{C} 2 \\
\mathrm{C} 2 \mathrm{H} 1 \\
\mathrm{C} 2 \mathrm{H} 2 \\
\mathrm{C} 2 \mathrm{H} 3 \\
\mathrm{C} 2 \mathrm{H} 4\end{array}$ & $\begin{array}{l}\text { Management involvement } \\
\text { Lack of company's safety policy } \\
\text { Insufficient safety training } \\
\text { Insufficient safety motivation and incentives } \\
\text { Negative management attitude to safety }\end{array}$ & {$[12,20,24,25,27-31]$} \\
\hline $\begin{array}{l}\mathrm{C} 3 \\
\mathrm{C} 3 \mathrm{H} 1 \\
\mathrm{C} 3 \mathrm{H} 2 \\
\end{array}$ & $\begin{array}{l}\text { Handling, storage, and use of materials. } \\
\text { Lack of proper planning and workforce for storage } \\
\text { Unsafe storage/stacking of materials and exceeding safe loading limits }\end{array}$ & {$[32-34]$} \\
\hline $\begin{array}{l}\mathrm{C} 4 \\
\mathrm{C} 4 \mathrm{H} 1 \\
\mathrm{C} 4 \mathrm{H} 2 \\
\mathrm{C} 4 \mathrm{H} 3\end{array}$ & $\begin{array}{c}\text { Welding and cutting } \\
\text { Failure in handling, inspection, and maintenance of equipment (cylinders, machines, hoses, and cables) } \\
\text { Lack of special PPE (personal protective equipment), such as face shield, special gloves, and goggles for welding/ } \\
\text { cutting } \\
\text { Welders without training, license, and certificates }\end{array}$ & {$[19,34-37]$} \\
\hline $\begin{array}{l}\mathrm{C} 5 \\
\mathrm{C} 5 \mathrm{H} 1 \\
\mathrm{C} 5 \mathrm{H} 2\end{array}$ & $\begin{array}{c}\text { Concrete and concrete framework } \\
\text { Failure to perform form works under the supervision of a competent person } \\
\text { Use of weak and deformed forms }\end{array}$ & {$[33,38]$} \\
\hline $\begin{array}{l}\mathrm{C} 6 \\
\mathrm{C} 6 \mathrm{H} 1 \\
\mathrm{C} 6 \mathrm{H} 2 \\
\mathrm{C} 6 \mathrm{H} 3\end{array}$ & $\begin{array}{c}\text { Crane and lifting equipment } \\
\text { Unavailability of a safe lift plan on-site } \\
\text { Lack of licensed trained riggers and operators } \\
\text { Lack of safe working load indicator/inspection stickers/latches/barricades }\end{array}$ & {$[34,37-40]$} \\
\hline $\begin{array}{l}\mathrm{C} 7 \\
\mathrm{C} 7 \mathrm{H} 1 \\
\mathrm{C} 7 \mathrm{H} 2 \\
\mathrm{C} 7 \mathrm{H} 3\end{array}$ & $\begin{array}{c}\text { Electrical equipment } \\
\text { Unsafe installation of the temporary power (old, damaged, and wrong rating of panels, sockets, wires, etc.) } \\
\text { Failure to apply access limit, lockout-tagout, permit system, and signage systems } \\
\text { Lack of inspection for the electric tools, cables, and equipment }\end{array}$ & {$[19,33,34,37]$} \\
\hline $\begin{array}{l}\mathrm{C} 8 \\
\mathrm{C} 8 \mathrm{H} 1 \\
\mathrm{C} 8 \mathrm{H} 2 \\
\mathrm{C} 8 \mathrm{H} 3\end{array}$ & $\begin{array}{c}\text { Hand and power tools and machinery } \\
\text { Tools are in bad condition with no regular inspection } \\
\text { Use of tools other than its intended use } \\
\text { Use or operation by untrained and unauthorized operators (lack of training system) }\end{array}$ & {$[20,24,33,34,41]$} \\
\hline $\begin{array}{l}\mathrm{C} 9 \\
\mathrm{C} 9 \mathrm{H} 1 \\
\mathrm{C} 9 \mathrm{H} 2 \\
\mathrm{C} 9 \mathrm{H} 3 \\
\mathrm{C} 9 \mathrm{H} 4\end{array}$ & $\begin{array}{l}\text { Working at height and protection against falling } \\
\text { Failure to place adequate barriers and warning signs for open edges and holes } \\
\text { Falling of hand tools and other materials } \\
\text { Failure to use required PPE (fall arrest systems) and safety nets } \\
\text { Unsafe access to high places by damaged ladders, lifts, etc. }\end{array}$ & {$[19,21,22,34,38]$} \\
\hline $\begin{array}{l}\mathrm{C} 10 \\
\mathrm{C} 10 \mathrm{H} 1 \\
\mathrm{C} 10 \mathrm{H} 2\end{array}$ & $\begin{array}{l}\text { Personal protective equipment } \\
\text { Failure to provide appropriate and adequate personal protective equipment for workers (head, eye, face, hand, } \\
\text { foot, and hearing protection) } \\
\text { Failure in enforcing, motivating, and training workers to use them. }\end{array}$ & {$[31$,} \\
\hline $\begin{array}{l}\mathrm{C} 11 \\
\mathrm{C} 11 \mathrm{H} 1 \\
\mathrm{C} 11 \mathrm{H} 2\end{array}$ & $\begin{array}{c}\text { Traffic and transportation control } \\
\text { Vehicles (buses/pickups/trucks/others) are in bad condition and do not have regular maintenance/first aid } \\
\text { equipment/fire extinguishers/lights } \\
\text { Failure in enforcing traffic regulations (seat belt, speed limit, license, and training) }\end{array}$ & {$[20,34,38,43]$} \\
\hline $\begin{array}{l}\mathrm{C} 12 \\
\mathrm{C} 12 \mathrm{H} 1 \\
\mathrm{C} 12 \mathrm{H} 2 \\
\mathrm{C} 12 \mathrm{H} 3 \\
\mathrm{C} 12 \mathrm{H} 4\end{array}$ & $\begin{array}{c}\text { Scaffolding and ladders } \\
\text { Use of defective and worn fasteners, components, settings, and material in scaffolding system } \\
\text { Lack of proper design, workmanship, and regular inspections } \\
\text { Inadequate scaffolding stability (guardrails, toe boards, secured ties, etc.) } \\
\text { Failure to provide safe access against slipping, sliding, or falling }\end{array}$ & {$[37,38,44,45]$} \\
\hline $\begin{array}{l}\mathrm{C} 13 \\
\mathrm{C} 13 \mathrm{H} 1 \\
\mathrm{C} 13 \mathrm{H} 2 \\
\mathrm{C} 13 \mathrm{H} 3 \\
\mathrm{C} 13 \mathrm{H} 4\end{array}$ & $\begin{array}{c}\text { Fire prevention } \\
\text { Lack of fire extinguishing training, escape plans, and drills } \\
\text { Failure in controlling of ignition sources and fire watches, fire blankets, etc } \\
\text { Fire extinguishers are not enough, not in proper locations, not accessible, and not regularly maintained } \\
\text { Failure in storage of flammable liquids and combustible materials }\end{array}$ & {$[19,34,37,46]$} \\
\hline $\begin{array}{l}\text { C14 } \\
\mathrm{C} 14 \mathrm{H} 1 \\
\mathrm{C} 14 \mathrm{H} 2 \\
\mathrm{C} 14 \mathrm{H} 3\end{array}$ & $\begin{array}{l}\text { Excavation, trenching, and shoring } \\
\text { Wrong procedures (with slab, timber, trench, boxes, shoring, lining, etc.) } \\
\text { Failure to locate underground services and to take precautionary measures } \\
\text { Lack of proper barriers/warning signs/lights for the excavation }\end{array}$ & {$[19,38]$} \\
\hline
\end{tabular}




\begin{tabular}{|c|c|c|c|c|c|c|c|c|c|} 
Choice & 1 & 2 & 3 & 4 & 5 & 6 & 7 & 8 & 9 \\
\hline Impact & No impact & $\longleftrightarrow$ & $\begin{array}{c}\text { Moderate } \\
\text { impact }\end{array}$ & $\longleftrightarrow$ & $\begin{array}{c}\text { Strong } \\
\text { impact }\end{array}$ & $\longleftarrow$ & $\begin{array}{c}\text { Very strong } \\
\text { impact }\end{array}$ & $\longleftrightarrow \begin{array}{c}\longleftarrow \\
\text { impact }\end{array}$ \\
\hline Frequency & $\begin{array}{c}\text { Unlikely } \\
\text { to happen }\end{array}$ & $\longleftrightarrow$ & May happen & $\longleftrightarrow$ & $\begin{array}{c}\text { Likely } \\
\text { to happen }\end{array}$ & $\longleftrightarrow$ & $\begin{array}{c}\text { Very likely } \\
\text { to happen }\end{array}$ & $\longleftrightarrow \begin{array}{c}\text { Certain } \\
\text { to happen }\end{array}$ \\
\hline
\end{tabular}

Figure 1: Scale definition for the importance and frequency levels for each hazard.

They mainly are construction engineers, managers, safety supervisions, design engineers, consultants, and owners. The questionnaire consists of 20 questions. The first 6 are related to the respondents' location, organization type and size, construction type, job designation, and total years of experience. Other 14 questions are related to scaling (1 to 9) of each hazard in terms of impact and frequency.

The questionnaire link was sent out by emails or via professional networks worldwide. Data collection resulted in 106 completed questionnaires. Contractors are the largest portion of respondents with 58 responses (54.7\%). Consultants, the second largest contributors of the survey, form almost $17 \%$ of the total participants. Project engineer and project/construction managers make a total of $60 \%$ of the responses. Participants involved in infrastructure and oil and gas construction projects hold the significant portion of participants with $28 \%$ and $23 \%$ of responses, respectively. Participants were categorized based on total years of work experiences in construction based on four groups, which are 0 to 5 years, 6 to 10,11 to 15 , and more than 16 years. A percentage of $40 \%$ of responses was yielded from professionals with experience between 6 and 10 years.

\section{Data Analysis}

One of the objectives of this paper is to get the perceptions of the construction professionals about the major safety hazards in construction projects. Survey participants rated each hazard importance and frequency based on a (1-9) scale. Participants were asked to evaluate the importance (the impact) of the hazard on safety performance. Frequency was also rated in order to decide on how often the hazard is come across in construction projects.

As an example, considering the factor "use of weak and deformed forms," the questions to the respondent related to this hazard are

(i) What is the impact of "use of weak and deformed forms" on safety performance?

(ii) How often the "use of weak and deformed forms" would likely to happen on a construction site?

The survey was sent to construction industry professionals. The data analysis is presented in the following sections.

5.1. Frequency-Adjusted Importance Index (FAII). A similar yet inventive ranking approach adopted in this research to rank safety attributes in the construction industry is the Frequency-Adjusted Importance Index (FAII) [35]. This technique considers both the importance and the frequency. In order to calculate the FAII, both the relative importance index (RII) and the frequency index (FI) are required. The equations for FAII, RII, and FI are shown below:

$$
\begin{aligned}
& \operatorname{RII}(\%)=\frac{\sum I}{A(N)} \times 100, \\
& \mathrm{FI}(\%)=\frac{\sum F}{A(N)} \times 100,
\end{aligned}
$$

where $I=$ weight given to importance by the respondent (1 to 9), $F$ = weight given to frequency by the respondents (1 to 9), $A=$ the highest weight (in this case 9), and $N=$ total number of respondents (in this case 106)

Based on both the RII (\%) and FI\% equations, the frequency-adjusted importance index will be calculated as follows:

$$
\operatorname{FAII}(\%)=\frac{(\mathrm{RII}(\%) \times \mathrm{FI} \%)}{100} .
$$

FAII provides better ranking results because it reflects the effects of importance and frequency all together.

5.2. Analytic Network Process (ANP). The ANP came as a generalized form of the AHP as many decision problems cannot be dealt with as a linear hierarchy structure. This is because of the existence of interdependences and interaction between the factors. While AHP depends on a hierarchical form of levels of goal, criteria, and subcriteria, the ANP deals with all factors as clusters in a network, which are all connected to the main goal (safety performance in this paper). The other advantage of the ANP is the network connecting the clusters and its elements together.

The safety performance in construction is a complex decision problem as many factors are interrelated. Hazards of a certain nature and under a certain category can have obvious influence and can develop other risks in a different category. Hence, it cannot be dealt as independent criteria. Similarly, hazards in a certain category can influence hazards under the same category. This is called the inner dependence, while the previously described relation between categories is called the outer dependence. In such problems, ANP would be a very powerful alternative to AHP and other methods.

Figure 2 illustrates the proposed ANP model. The model is a network that consists of categories called clusters. Each cluster contains the elements, which are called the hazards. The safety performance is connected to all clusters. Until this 
stage, the model is linear and categories are independent. The red and black arrows represent the interdependences, which is the nonlinear part of the model. As explained, these show the effect of relevant hazards in influencing others. As an example, the $\mathrm{C} 2 \mathrm{H} 1$, "lack of safety policy" has its influence on $\mathrm{C} 10 \mathrm{H} 2$, "failure in enforcing use of PPE."

The steps to implement ANP model can be seen in Figure 3. Steps one and two are presented in Figure 2. The 3rd step is to develop a pairwise comparison between the elements in a matrix format and then to put these submatrices together to form the unweighted supermatrix (Figure 4). The pairwise comparison is calculated based on FAII ranking of factors. As an example, the FAII rank of $\mathrm{C} 1 \mathrm{H} 2$ is 5 , while the FAII rank of $\mathrm{C} 1 \mathrm{H} 3$ is 29 . The difference in ranking is 24 . Using linear interpolation to scale the differences in a (1-9) scale by considering the maximum rank difference of 31 (maximum rank difference is between factors $\mathrm{C} 4 \mathrm{H} 1$ and $\mathrm{C} 4 \mathrm{H} 2$ ), the result will be $7 / 9$. The scaling table can be seen in Table 2. And this is inserted in the W11 matrix in Figure 4. The rest of the pairwise comparison was similarly carried out.

The fourth step is to do pairwise comparison at the cluster level to develop the cluster matrix. The weight of the cluster is determined by the weights of its components, which are the nodes (in this case "hazards"). The average value of the hazard weight in FAII was already calculated for the main category. As an example, weight of $\mathrm{C} 1=(\mathrm{C} 1 \mathrm{H} 1+\mathrm{C} 1 \mathrm{H} 2+\mathrm{C} 1 \mathrm{H} 3) / 3$, which is $(0.32404+$ $0.35800+0.29878) / 3=0.3269$. Similarly, cluster weights were calculated for all main categories.

Multiplication of each block in the unweighted supermatrix by the weight of the corresponding cluster weight will result in the weighted supermatrix. Raising the weighted supermatrix to high power will make it convergent as the limiting matrix. The results are the rank of the hazards, which is given by the priority vector in the limit matrix. These calculations can be carried out with the help of software such as SuperDecision. The result of FAII and ANP can be seen in Table 3 below.

From Table 3, it was seen that the top 5 ranked safety hazards based on ANP results are (1) lack of company's safety policy, (2) insufficient safety training, (3) failure in enforcing, motivating, and training workers to use PPE, (4) no housekeeping (scattered garbage and material, dusts, excessive noise, vibration, etc.), and (5) insufficient safety motivation and incentives.

5.3. Safety Performance Index (SPI). The previous results will be utilized to measure the safety performance in construction sites. The 42 hazards will be used to measure safety performance in construction sites. These hazards will be used for calculating SPI (safety performance index), which then can be used to measure safety performance in construction sites, compare sites together, and benchmarking.

The main idea is to do site inspection focusing on these hazards and evaluate if the site under inspection is complying with the safety procedures to avoid such hazard. Compliance will be given a weight of $100 \%$ and noncompliance will be $0 \%$. Then, the safety index will be the site compliance for each hazard, multiplied by the limiting vector of the hazards.

The SPI can be given according to the following formula:

$$
\mathrm{SPI}=\Sigma L \cdot E,
$$

where $L$ is the limiting vector resulted from the ANP, which is normalized for all hazards, and the summation will equal to 1 , and $E$ is site evaluation of each hazard $(0-100 \%)$ measured by a safety expert.

However, the formula is not considering that some of the hazards can be not applicable in some construction sites due to the type of construction. As an example, welding is not considered as hazard in the building site and concrete work can be ignored in a mechanical pipeline project. In such cases, inapplicable hazards are ignored, and then all other hazards will be normalized to the new summation.

The new limiting vector can be called Ln (normalized limiting vector). The final general formula will be

$$
\mathrm{SPI}=\Sigma L_{n} \cdot E,
$$

where $L_{n}$ is the normalized limiting vector and $\mathrm{E}$ is site evaluation of each hazard $(0-100 \%)$ measured by safety expert.

As an example, refer to Table 4 below. It shows the calculation of an SPI for a random construction site. The safety index is found to be $83.7 \%$. The same table is showing the safety index of each main category. C1-"site planning and housekeeping" is 58.3 and C2-"management involvement" is 88.4, etc. that some hazards are not applicable. Each category's SPI index was calculated by the formula below. This calculation helps the construction team to take action against each category:

$$
\operatorname{SPI}(\text { each category })=\frac{\Sigma L_{n} \cdot E}{\Sigma 100 * L_{n}} .
$$

\section{Discussion of Results and Practical Implications}

42 hazards in 14 categories were identified and offered in a survey after reviewing the literature. The survey was distributed to construction industry professionals. 106 respondents assessed the 42 hazards based on impact (the hazard impact on safety performance in construction projects) and frequency (how often the hazard is likely to happen). The collected data of 106 responses were then analyzed by frequency-adjusted importance index.

The resulted ranking of the hazards was then utilized to perform ANP (Analytic Network Process) as a second stage ranking tool in a purpose to reveal the root causes of these hazards. The ANP was selected as it is a powerful multicriteria decision-making technique for complex problems. The complexity is due to the existence of interdependencies between hazards from or across different categories.

It can be concluded from Table 3 that the hazards, which is considered most significant, is the "lack of company's 


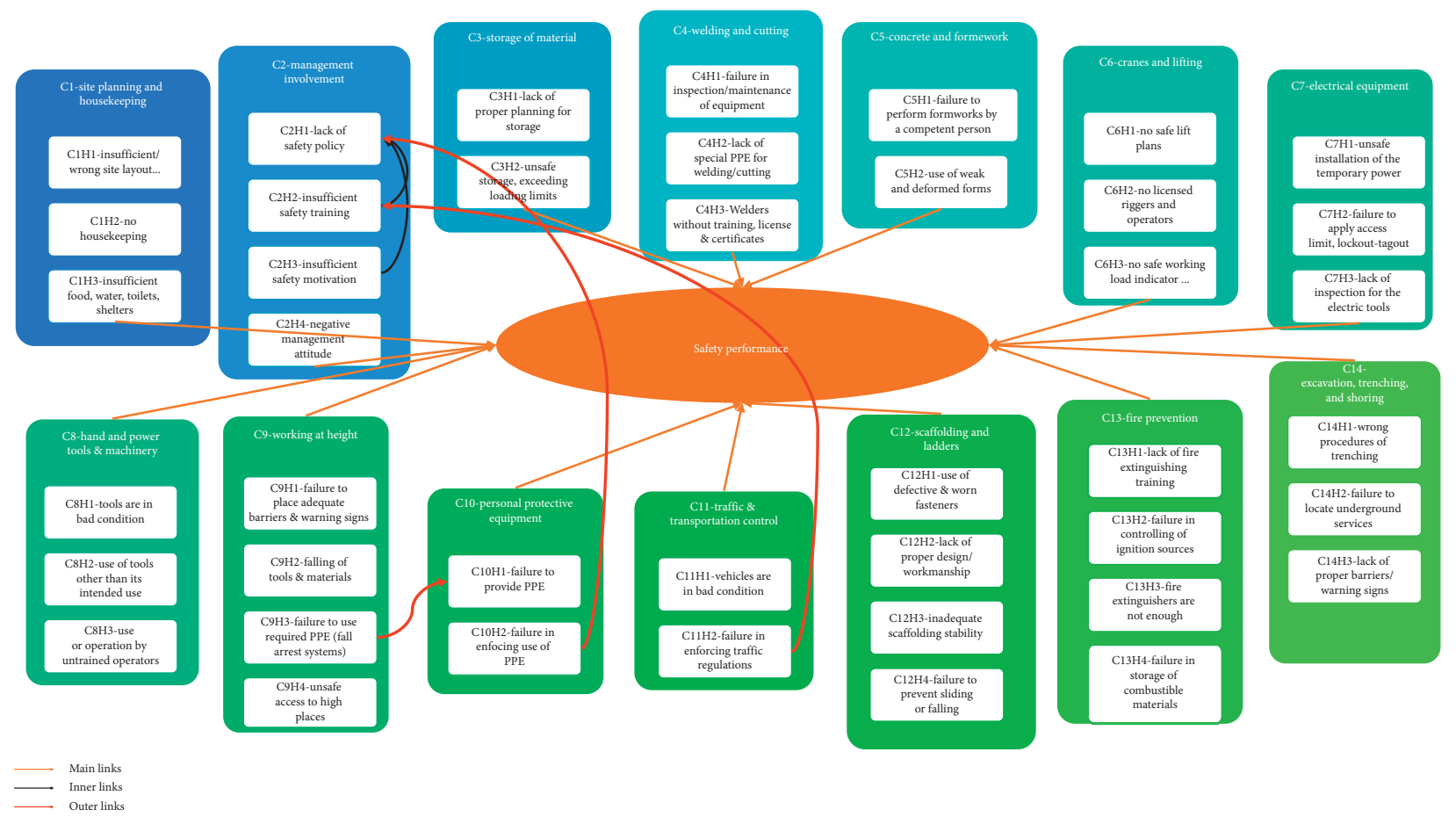

FIGURE 2: ANP safety performance model with relevant categories.

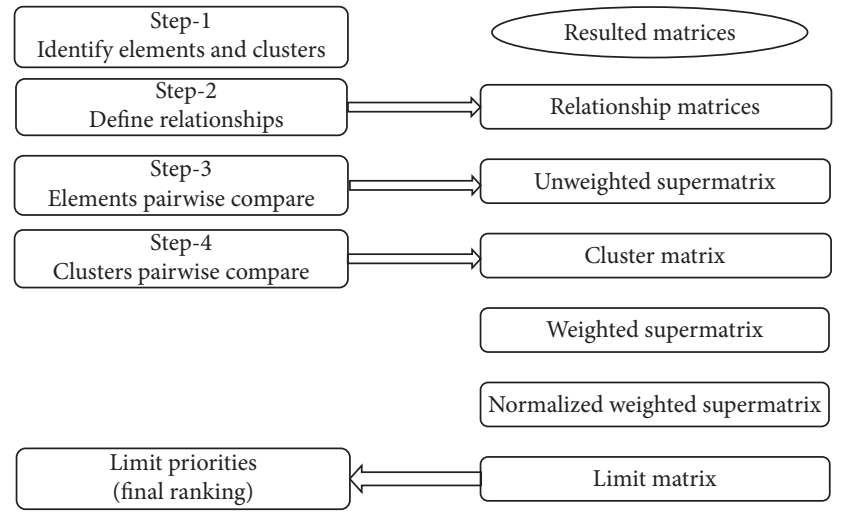

Figure 3: ANP implementation steps and resulting matrices at each step.

safety policy" (ANP rank 1). This is related to the organization safety management at the planning phase of the project. The safety policy is a strong evidence of commitment toward safety and the methods to implement safety procedures on-site. It is to be noted that this ranked $19^{\text {th }}$ in FAII. This result shows the strength of the ANP technique in representing the real causes, or the latent hazards, which stand behind many hazards. "Insufficient safety training" (ANP rank 2) is another hazard under the management category. This hazard ranked the first in FAII, and to which most of the accident in construction is referred. This hazard is explicit and latent, as many other hazards are connected to it. "Failure in enforcing, motivating, and training workers to use PPE" ranked as third in ANP compared to seventh in FAII. This is also considered as a latent or causing hazard of many hazards related to using PPE such as the "failure to use

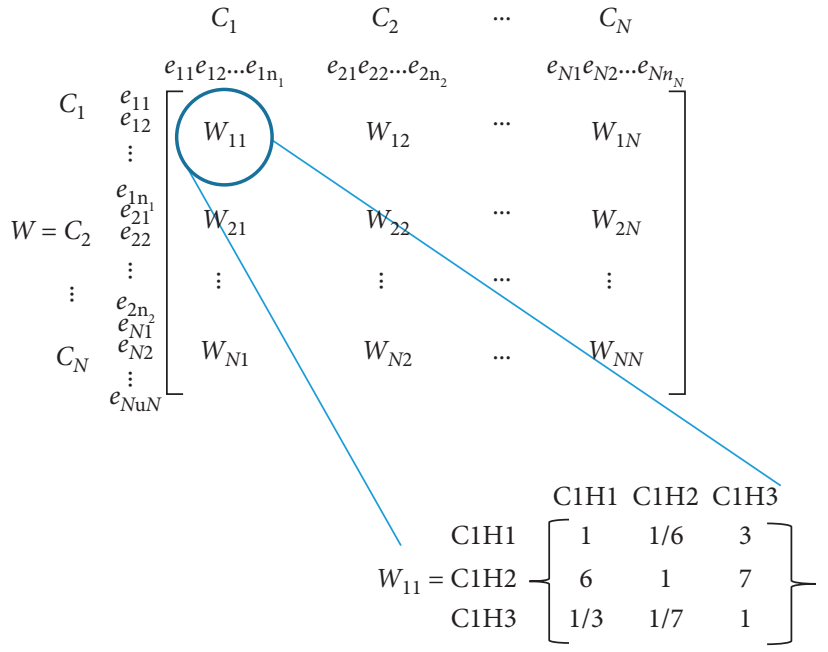

FIGURE 4: The supermatrix formulation.

required PPE (fall arrest systems) and safety nets," which ranked 4th in FAII.

In this study, it has been proved that safety experts shall focus their attention to the root cause of the hazards, that is, the latent hazards, which actually drive the accidents and injuries. However, focusing on solving the apparent hazards in a reactive way would not improve safety performance and will keep such hazards repeating as long as construction is ongoing. Hence, the most important is to solve the root causes of the problems.

From the study, it has been found that management involvement is the most important factor in improving the safety performance by adopting a robust clear safety policy, which shall include safety and craft training, motivation and 
TABLE 2: Scaling table through linear interpolation based on the differences between the factors.

\begin{tabular}{lccc}
\hline Difference & $(1-9)$ scale & Difference & $(1-9)$ scale \\
\hline 1 & 2 & 17 & 6 \\
2 & 2 & 18 & 6 \\
3 & 2 & 19 & 6 \\
4 & 3 & 20 & 6 \\
5 & 3 & 21 & 7 \\
6 & 3 & 22 & 7 \\
7 & 3 & 23 & 7 \\
8 & 4 & 24 & 7 \\
9 & 4 & 25 & 8 \\
10 & 4 & 26 & \\
11 & 4 & 27 & \\
12 & 5 & 28 & \\
13 & 5 & 29 & 9 \\
14 & 5 & 30 & 9 \\
16 & 5 & 31 & 9 \\
\hline
\end{tabular}

TABLE 3: FAII (\%) values and ranking of safety attributes by ANP.

\begin{tabular}{|c|c|c|c|c|c|}
\hline CODE & Name & FAII & $\begin{array}{c}\text { Rank } \\
1\end{array}$ & ANP & $\begin{array}{c}\text { Rank } \\
2 \downarrow\end{array}$ \\
\hline $\mathrm{C} 2 \mathrm{H} 1$ & Lack of company's safety policy & 0.28753 & 19 & 0.271236 & 1 \\
\hline $\mathrm{C} 2 \mathrm{H} 2$ & Insufficient safety training & 0.40116 & 1 & 0.080684 & 2 \\
\hline $\mathrm{C} 10 \mathrm{H} 2$ & Failure in enforcing, motivating, and training workers to use PPE & 0.32259 & 7 & 0.074344 & 3 \\
\hline $\mathrm{C} 1 \mathrm{H} 2$ & No housekeeping (scattered garbage and material, dusts, excessive noise, vibration, etc.) & 0.33981 & 5 & 0.054578 & 4 \\
\hline $\mathrm{C} 2 \mathrm{H} 3$ & Insufficient safety motivation and incentives & 0.39506 & 2 & 0.052904 & 5 \\
\hline $\mathrm{C} 9 \mathrm{H} 3$ & Failure to use required PPE (fall arrest systems) and safety nets & 0.34568 & 4 & 0.051955 & 6 \\
\hline $\mathrm{C} 2 \mathrm{H} 4$ & Negative management attitude to safety & 0.38752 & 3 & 0.03552 & 7 \\
\hline $\mathrm{C} 9 \mathrm{H} 2$ & Falling of hand tools and other materials & 0.32693 & 6 & 0.032775 & 8 \\
\hline $\mathrm{C} 14 \mathrm{H} 2$ & Failure to locate underground services and to take precautionary measures & 0.31173 & 11 & 0.031273 & 9 \\
\hline $\mathrm{C} 11 \mathrm{H} 2$ & Failure in enforcing traffic regulations (seat belt, speed limit, license, and training) & 0.30476 & 13 & 0.0285 & 10 \\
\hline $\mathrm{C} 13 \mathrm{H} 4$ & Failure in storage of flammable liquids and combustible materials & 0.31005 & 12 & 0.027115 & 11 \\
\hline $\mathrm{C} 6 \mathrm{H} 3$ & Lack of safe working load indicator/inspection stickers/latches/barricades & 0.31981 & 8 & 0.02209 & 12 \\
\hline $\mathrm{C} 9 \mathrm{H} 1$ & Failure to place adequate barriers and warning signs for open edges and holes & 0.31855 & 9 & 0.019644 & 13 \\
\hline $\mathrm{C} 4 \mathrm{H} 2$ & $\begin{array}{c}\text { Lack of special PPE (personal protective equipment), such as face shield, special gloves, and } \\
\text { goggles for welding/cutting }\end{array}$ & 0.31741 & 10 & 0.019333 & 14 \\
\hline $\mathrm{C} 7 \mathrm{H} 1$ & $\begin{array}{c}\text { Unsafe installation of the temporary power (old, damaged, and wrong rating of panels, } \\
\text { sockets, wires, etc.) }\end{array}$ & 0.2758 & 24 & 0.018633 & 15 \\
\hline $\mathrm{C} 8 \mathrm{H} 3$ & Use or operation by untrained and unauthorized operators (lack of training system) & 0.29729 & 15 & 0.01509 & 16 \\
\hline $\mathrm{C} 10 \mathrm{H} 1$ & $\begin{array}{l}\text { Failure to provide appropriate and adequate personal protective equipment for workers } \\
\text { (head, eye, face, hand, foot, and hearing protection) }\end{array}$ & 0.28235 & 20 & 0.014869 & 17 \\
\hline $\mathrm{C} 13 \mathrm{H} 3$ & $\begin{array}{c}\text { Fire extinguishers are not enough, not in proper locations, not accessible, and not regularly } \\
\text { maintained }\end{array}$ & 0.29127 & 17 & 0.014117 & 18 \\
\hline $\mathrm{C} 14 \mathrm{H} 3$ & Lack of proper barriers/warning signs/lights for the excavation & & 1 & & 19 \\
\hline $\mathrm{C} 3 \mathrm{H} 2$ & Unsafe storage/stacking of materials and exce & 0.29321 & 16 & 0.01 & 20 \\
\hline $\mathrm{C} 1 \mathrm{H} 1$ & Insufficient working spaces/wrong site layout/no access/no lights & 0.28045 & 22 & 0.012462 & 21 \\
\hline $\mathrm{C} 7 \mathrm{H} 2$ & Failure to apply access limit, lockout tag-out, permit system, and signage systems & 0.26612 & 26 & 0.011738 & 22 \\
\hline $\mathrm{C} 12 \mathrm{H} 3$ & Inadequate scaffolding stability (guardrails, toe boards, secured ties, etc.) & 0.2809 & 21 & 0.009772 & 23 \\
\hline $\mathrm{C} 9 \mathrm{H} 4$ & Unsafe access to high places by damaged ladders, lifts, etc. & 0.30041 & 14 & 0.008982 & 24 \\
\hline $\mathrm{C} 7 \mathrm{H} 3$ & Lack of inspection for the electric tools, cables, and equipment & 0.26452 & 27 & 0.007395 & 25 \\
\hline $\mathrm{C} 6 \mathrm{H} 2$ & Lack of licensed trained riggers and operators & 0.27984 & 23 & 0.005696 & 26 \\
\hline $\mathrm{C} 1 \mathrm{H} 3$ & Insufficient food, drinking water, toilets, rest shelters, and medical facilities & 0.26155 & 29 & 0.005691 & 27 \\
\hline $\mathrm{C} 13 \mathrm{H} 2$ & Failure in controlling of ignition sources and fire watches, fire blankets, etc. & 0.26296 & 28 & 0.005473 & 28 \\
\hline $\mathrm{C} 5 \mathrm{H} 1$ & Failure to perform form works under the supervision of a competent person & 0.21498 & 39 & 0.005426 & 29 \\
\hline $\mathrm{C} 12 \mathrm{H} 4$ & Failure to provide safe access against slipping, sliding, or falling & 0.27511 & 25 & 0.005256 & 30 \\
\hline $\mathrm{C} 11 \mathrm{H}$ & $\begin{array}{c}\text { Vehicles (buses/pickups/trucks/others) are in bad condition and do not have regular } \\
\text { maintenance/first aid equipment/fire extinguishers/lights }\end{array}$ & 0.2 & 31 & 0.004 & 1 \\
\hline $\mathrm{C} 4 \mathrm{H} 3$ & Welders without training, license, and certificates & 0.2 & 34 & 0.003663 & 32 \\
\hline $\mathrm{C} 14 \mathrm{H} 1$ & Wrong procedures (with slab, timber, trench, boxes, shoring, lining, etc.) & 0.25274 & 33 & 0.003465 & 33 \\
\hline
\end{tabular}


TABle 3: Continued.

\begin{tabular}{|c|c|c|c|c|c|}
\hline CODE & Name & FAII & $\begin{array}{c}\text { Rank } \\
1\end{array}$ & ANP & $\begin{array}{c}\text { Rank } \\
2 \downarrow\end{array}$ \\
\hline $\mathrm{C} 8 \mathrm{H} 2$ & Use of tools other than its intended use & 0.24863 & 35 & 0.00301 & 34 \\
\hline $\mathrm{C} 13 \mathrm{H} 1$ & Lack of fire extinguishing training, escape plans, and drills & 0.25591 & 32 & 0.002861 & 35 \\
\hline $\mathrm{C} 5 \mathrm{H} 2$ & Use of weak and deformed forms & 0.19334 & 42 & 0.002713 & 36 \\
\hline $\mathrm{C} 6 \mathrm{H} 1$ & Unavailability of a safe lift plan on-site & 0.25873 & 30 & 0.002448 & 37 \\
\hline $\mathrm{C} 3 \mathrm{H} 1$ & Lack of proper planning and workforce for storage & 0.20988 & 40 & 0.001829 & 38 \\
\hline $\mathrm{C} 12 \mathrm{H} 2$ & Lack of proper design, workmanship, and regular inspections & 0.23285 & 36 & 0.001809 & 39 \\
\hline $\mathrm{C} 8 \mathrm{H} 1$ & Tools are in bad condition with no regular inspection & 0.21674 & 38 & 0.001801 & 40 \\
\hline $\mathrm{C} 4 \mathrm{H} 1$ & $\begin{array}{c}\text { Failure in handling, inspection, and maintenance of equipment (cylinders, machines, hoses, } \\
\text { and cables) }\end{array}$ & 0.19444 & 41 & 0.00162 & 41 \\
\hline $\mathrm{C} 12 \mathrm{H} 1$ & $\begin{array}{l}\text { Use of defective and worn fasteners, components, settings, and material in scaffolding } \\
\text { system }\end{array}$ & 0.23167 & 37 & 0.001233 & 42 \\
\hline
\end{tabular}

TABle 4: Safety performance index calculation.

\begin{tabular}{|c|c|c|c|c|c|c|c|}
\hline Category & Code & Name & $\begin{array}{l}\text { Limiting } \\
\text { vector } \\
L\end{array}$ & $\begin{array}{c}\text { Limiting } \\
\text { (normalized) } \\
L_{n} \\
\end{array}$ & $\begin{array}{c}\text { Evaluation of } \\
\text { hazard } \\
E\end{array}$ & $L_{n} E$ & $\begin{array}{l}\text { SPI per } \\
\text { category }\end{array}$ \\
\hline \multirow{3}{*}{$\mathrm{C} 1$} & $\mathrm{C} 1 \mathrm{H} 1$ & $\begin{array}{c}\text { Insufficient working spaces/wrong site layout/no } \\
\text { access/no lights }\end{array}$ & 0.0123 & 0.0132 & 80 & 1.1 & \multirow{3}{*}{58.3} \\
\hline & $\mathrm{C} 1 \mathrm{H} 2$ & $\begin{array}{c}\text { No housekeeping (scattered garbage and material, } \\
\text { dusts, excessive noise, vibration, etc.) }\end{array}$ & 0.0538 & 0.0579 & 50 & 2.9 & \\
\hline & $\mathrm{C} 1 \mathrm{H} 3$ & $\begin{array}{l}\text { Insufficient food, drinking water, toilets, rest } \\
\text { shelters, and medical facilities }\end{array}$ & 0.0056 & 0.006 & 90 & 0.5 & \\
\hline \multirow{4}{*}{$\mathrm{C} 2$} & $\mathrm{C} 2 \mathrm{H} 1$ & Lack of company's safety policy & 0.2799 & 0.3012 & 90 & 27.1 & \multirow{4}{*}{88.4} \\
\hline & $\mathrm{C} 2 \mathrm{H} 2$ & Insufficient safety training & 0.0813 & 0.0875 & 90 & 7.9 & \\
\hline & $\mathrm{C} 2 \mathrm{H} 3$ & Insufficient safety motivation and incentives & 0.0521 & 0.0561 & 80 & 4.5 & \\
\hline & $\mathrm{C} 2 \mathrm{H} 4$ & Negative management attitude to safety & 0.035 & 0.0377 & 85 & 3.2 & \\
\hline \multirow[b]{2}{*}{$\mathrm{C} 3$} & $\mathrm{C} 3 \mathrm{H} 1$ & Lack of proper planning and workforce for storage & 0.0018 & 0.0019 & 70 & 0.1 & \multirow[b]{2}{*}{78.7} \\
\hline & $\mathrm{C} 3 \mathrm{H} 2$ & $\begin{array}{c}\text { Unsafe storage/stacking of materials and exceeding } \\
\text { safe loading limits }\end{array}$ & 0.0126 & 0.0136 & 80 & 1.1 & \\
\hline \multirow{3}{*}{$\mathrm{C} 4$} & $\mathrm{C} 4 \mathrm{H} 1$ & $\begin{array}{l}\text { Failure in handling, inspection, and maintenance of } \\
\text { equipment (cylinders, machines, hoses, and cables) }\end{array}$ & 0.0016 & 0.0017 & 80 & 0.1 & \multirow{3}{*}{70.7} \\
\hline & $\mathrm{C} 4 \mathrm{H} 2$ & $\begin{array}{l}\text { Lack of special PPE (personal protective } \\
\text { equipment), such as face shield, special gloves, and } \\
\text { goggles for welding/cutting }\end{array}$ & 0 & 0 & 70 & 0 & \\
\hline & $\mathrm{C} 4 \mathrm{H} 3$ & Welders without training, license, and certificates & 0.0036 & 0.0039 & 70 & 0.3 & \\
\hline \multirow[t]{2}{*}{ C5 } & $\mathrm{C} 5 \mathrm{H} 1$ & $\begin{array}{l}\text { Failure to perform form works under the } \\
\text { supervision of a competent person }\end{array}$ & 0.0053 & 0.0058 & 85 & 0.5 & \multirow[t]{2}{*}{83.7} \\
\hline & $\mathrm{C} 5 \mathrm{H} 2$ & Use of weak and deformed forms & 0 & 0 & 81 & 0 & \\
\hline \multirow{3}{*}{ C6 } & $\mathrm{C} 6 \mathrm{H} 1$ & Unavailability of a safe lift plan on-site & 0.0024 & 0.0026 & 56 & 0.1 & \multirow{3}{*}{82.1} \\
\hline & $\mathrm{C} 6 \mathrm{H} 2$ & Lack of licensed trained riggers and operators & 0.0056 & 0.006 & 55 & 0.3 & \\
\hline & $\mathrm{C} 6 \mathrm{H} 3$ & $\begin{array}{c}\text { Lack of safe working load indicator/inspection } \\
\text { stickers/latches/barricades }\end{array}$ & 0.0218 & 0.0234 & 92 & 2.2 & \\
\hline \multirow{3}{*}{$\mathrm{C} 7$} & $\mathrm{C} 7 \mathrm{H} 1$ & $\begin{array}{l}\text { Unsafe installation of the temporary power (old, } \\
\text { damaged, and wrong rating of panels, sockets, wires, } \\
\text { etc.) }\end{array}$ & 0.0184 & 0.0198 & 81 & 1.6 & \multirow{3}{*}{71.7} \\
\hline & $\mathrm{C} 7 \mathrm{H} 2$ & $\begin{array}{l}\text { Failure to apply access limit, lockout-tagout, permit } \\
\text { system, and signage systems }\end{array}$ & 0 & 0 & 61 & 0 & \\
\hline & $\mathrm{C} 7 \mathrm{H} 3$ & $\begin{array}{c}\text { Lack of inspection for the electric tools, cables, and } \\
\text { equipment }\end{array}$ & 0.0073 & 0.0078 & 65 & 0.5 & \\
\hline \multirow{3}{*}{$\mathrm{C} 8$} & $\mathrm{C} 8 \mathrm{H} 1$ & $\begin{array}{c}\text { Tools are in bad condition with no regular } \\
\text { inspection. }\end{array}$ & 0.0018 & 0.0019 & 73 & 0.1 & \multirow{3}{*}{90.4} \\
\hline & $\mathrm{C} 8 \mathrm{H} 2$ & Use of tools other than its intended use & 0.003 & 0.0032 & 98 & 0.3 & \\
\hline & $\mathrm{C} 8 \mathrm{H} 3$ & $\begin{array}{l}\text { Use or operation by untrained and unauthorized } \\
\text { operators (lack of training system) }\end{array}$ & 0.0149 & 0.016 & 91 & 1.5 & \\
\hline
\end{tabular}


TABLE 4: Continued.

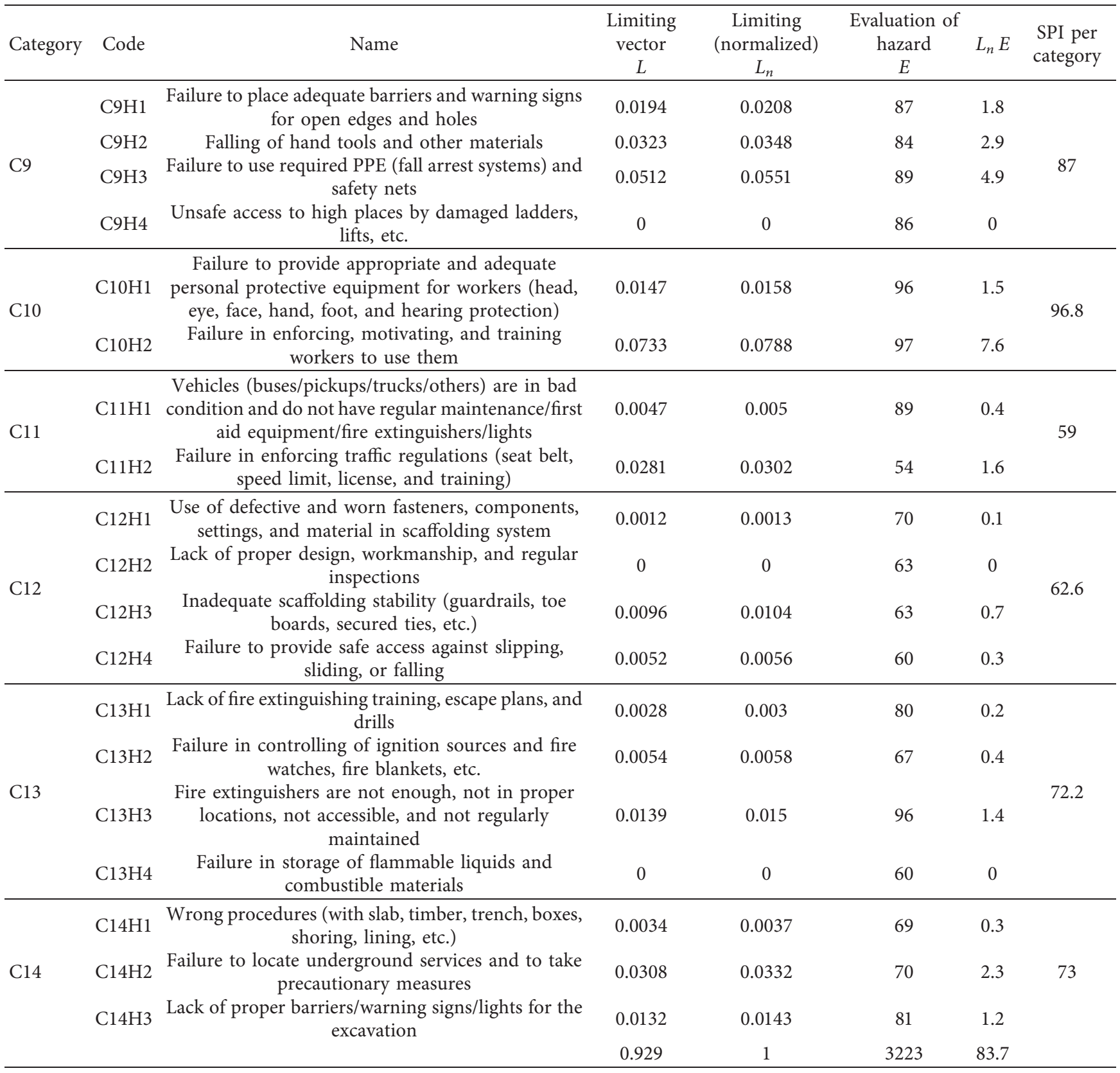

incentives, and enforcing and accountability toward safety in all levels of the work force. This proactive attitude will help make safety as a culture at the construction sites. Therefore, the recommendation to construction industry leadership is to focus on safety policies and management commitment to safety when selecting their stakeholders of consultants and contractors.

Furthermore, this paper recommends safety experts to identify hazards, prioritize them, and distribute the budget wisely to prevent accidents.

\section{Conclusion}

The construction industry is considered risky as labor and machinery intense environment interacts with accelerating and overlapping activities. This situation would result in high number of accidents and fatalities. High number of accidents and fatalities lead to additional cost and delay on all stakeholders including public agencies, project owners, development companies, consultants, and construction companies. Identifying hazards and quantifying their impacts on construction safety are crucial for planning, budgeting, and management purposes. Safety hazards ranking is a complex process as these hazards are interconnected. There is a gap in the literature to study the interconnections of these hazards along with their frequency of occurrences. This is the first study in the literature to combine frequency adjusted importance index and ANP tool together. Past literature conducted targeting the safety performance evaluation were focusing on identifying the 
observable hazards and evaluating their apparent effects. A frequency-adjusted importance index analysis was carried out in this paper as a first stage by ranking the hazards. The top three hazards according to FAII were (1) insufficient safety training, (2) negative management attitude to safety, and (3) insufficient safety motivation and incentives.

A second stage ranking was carried out by using the ANP (Analytic Network Process). This technique has proven its benefits in solving complex decision problems due to existence of interdependences between its parts, which is the case in safety hazards where some hazards are interrelated. The ANP ranking gave a close ranking similar to FAII where the top three hazards were (1) lack of company's safety policy, (2) insufficient safety training, and (3) failure in enforcing, motivating, and training workers to use PPE.

The results of both analyses confirm that the role the management plays is an important role to improve the safety performance by establishing a safety policy, adopting safetytraining procedures, enforce safety procedures through incentives, and control measures.

The outcome of this paper would help the construction and the safety professionals on assessing and quantifying the most critical safety hazards in the construction industry. Moreover, the construction and safety professionals would utilize the safety performance index calculation to quantitatively measure their site safety level.

This study could be extended further by developing a practical tool to measure the safety performance index and conducting case studies on comparison of the safety performance index in construction projects.

\section{Data Availability}

The data used to support the findings of this study are available from the corresponding author upon request.

\section{Conflicts of Interest}

The authors declare that they have no conflicts of interest.

\section{References}

[1] R. Akram, M. J. Thaheem, A. R. Nasir, T. H. Ali, and S. Khan, "Exploring the role of building information modeling in construction safety through science mapping," Safety Science, vol. 120, pp. 456-470, 2019.

[2] M. T. Trinh and Y. Feng, "Impact of project complexity on construction safety performance: moderating role of resilient safety culture," Journal of Construction Engineering and Management, vol. 146, no. 2, Article ID 04019103, 2020.

[3] K. Versteeg, P. Bigelow, A. M. Dale, and A. Chaurasia, "Utilizing construction safety leading and lagging indicators to measure project safety performance: a case study," Safety Science, vol. 120, pp. 411-421, 2019.

[4] M. D. Martínez-Aires, M. López-Alonso, and M. MartínezRojas, "Building information modeling and safety management: a systematic review," Safety Science, vol. 101, pp. 11-18, 2018.

[5] S. Alizadehsalehi, I. Yitmen, T. Celik, and D. Arditi, "The effectiveness of an integrated BIM/UAV model in managing safety on construction sites," International Journal of
Occupational Safety and Ergonomics, vol. 10, pp. 1-16. in Press, 2018.

[6] D. G. C. Jamot and J. Y. Park, "System theory based hazard analysis for construction site safety: a case study from Cameroon," Safety Science, vol. 118, pp. 783-794, 2019.

[7] A. Ardeshir and M. Mohajeri, "Assessment of safety culture among job positions in high-rise construction: a hybrid fuzzy multi criteria decision-making (FMCDM) approach," International Journal of Injury Control and Safety Promotion, vol. 25, no. 2, pp. 195-206, 2018.

[8] T. Yang, P. Song, J. Liu, and M. Wang, "The assessment of metro station construction safety risk based on ANP-grey clustering method," in Proceedings of the 7th International Symposium on Project Management, ISPM, pp. 153-158, Chongqing, China, July 2019.

[9] J.-L. Zhou, Z.-H. Bai, and Z.-Y. Sun, "A hybrid approach for safety assessment in high-risk hydropower-constructionproject work systems," Safety Science, vol. 64, pp. 163-172, 2014.

[10] L. S. Marín, H. Lipscomb, M. Cifuentes, and L. Punnett, "Perceptions of safety climate across construction personnel: associations with injury rates," Safety Science, vol. 118, pp. 487-496, 2019.

[11] W. M. Alruqi and M. R. Hallowell, "Critical success factors for construction safety: review and meta-analysis of safety leading indicators," Journal of Construction Engineering and Management, vol. 145, no. 3, Article ID 04019005, 2019.

[12] M. Grill and K. Nielsen, "Promoting and impeding safety-a qualitative study into direct and indirect safety leadership practices of constructions site managers," Safety Science, vol. 114, pp. 148-159, 2019.

[13] Y. Han, R. Jin, H. Wood, and T. Yang, "Investigation of demographic factors in construction employees' safety perceptions," KSCE Journal of Civil Engineering, vol. 23, no. 7, pp. 2815-2828, 2019.

[14] A. Mohammadi, M. Tavakolan, and Y. Khosravi, "Factors influencing safety performance on construction projects: a review," Safety Science, vol. 109, pp. 382-397, 2018.

[15] M. T. Newaz, P. R. Davis, M. Jefferies, and M. Pillay, "Developing a safety climate factor model in construction research and practice: a systematic review identifying future directions for research," Engineering, Construction and Architectural Management, vol. 25, no. 6, pp. 738-757, 2018.

[16] Q. Suo and D. Zhang, "Investigation and identification of factors affecting migrating peasant workers' usage of safety footwear in the Chinese construction industry," International Journal of Occupational Safety and Ergonomics, vol. 23, no. 3, pp. 424-430, 2017.

[17] J. Wang, P. X. W. Zou, and P. P. Li, "Critical factors and paths influencing construction workers' safety risk tolerances," Accident Analysis \& Prevention, vol. 93, pp. 267-279, 2016.

[18] W. Zhang, X. Zhang, X. Luo, and T. Zhao, "Reliability model and critical factors identification of construction safety management based on system thinking," Journal of Civil Engineering and Management, vol. 25, no. 4, pp. 362-379, 2019.

[19] M. Gunduz, M. T. Birgonul, and M. Ozdemir, "Fuzzy structural equation model to assess construction site safety performance," ASCE Journal of Construction Engineering and Management, vol. 143, no. 4, 2017.

[20] B. Esmaeili, M. Hallowell, and B. Rajagopalan, "Attribute based safety risk assessment. II: predicting safety outcomes using generalized linear models," Journal of Construction 
Engineering and Management, vol. 141, no. 8, Article ID 04015022, 2015.

[21] A. S. J. Holt, Principles of Construction Safety, Blackwell Science Ltd., Oxford, UK, 2006.

[22] O. A. Jannadi and M. S. Bu-Khamsin, "Safety factors considered by industrial contractors in Saudi Arabia," Building and Environment, vol. 37, no. 5, pp. 539-547, 2002.

[23] A. N. Kheni, A. G. F. Gibb, and A. R. J. Dainty, "The management of construction site health and safety by small and medium-sized construction businesses in developing countries: a Ghana case study," in Proceedings of the 22nd Annual ARCOM Conference, pp. 295-304, Birmingham, UK, September 2006.

[24] S. Rajendran and J. A. Gambatese, "Development and initial validation of sustainable construction safety and health rating system," Journal of Construction Engineering and Management, vol. 135, no. 10, pp. 1067-1075, 2009.

[25] C. D. Reese and J. V. Eidson, OSHA Construction Safety and Health, Lewis Publishers, Boca Raton, FL, USA, 1999.

[26] C. Sooyoung and L. Fernanda, "Construction safety planning: site-specific temporal and spatial information integration," Automation in Construction, vol. 84, pp. 335-344, 2017.

[27] A. R. Abdul Hamid, M. Z. Abd Majid, and B. Singh, "Causes of accidents at construction sites," Malaysian Journal of Civil Engineering, vol. 20, no. 2, pp. 242-259, 2008.

[28] S. Aminbakhsh, M. Gunduz, and R. Sonmez, "Safety risk assessment using analytic hierarchy process (AHP) during planning and budgeting of construction projects," Journal of Safety Research, vol. 46, pp. 99-105, 2013.

[29] M. Gunduz and H. Laitinen, "A 10-step safety management framework for construction small and medium-sized enterprises," International Journal of Occupational Safety and Ergonomics, vol. 23, no. 3, pp. 353-359, 2017.

[30] M. Gunduz, M. Talat Birgonul, and M. Ozdemir, "Development of a safety performance index assessment tool by using a fuzzy structural equation model for construction sites," $A u$ tomation in Construction, vol. 85, pp. 124-134, 2018.

[31] C. M. Tam, S. X. Zeng, and Z. M. Deng, "Identifying elements of poor construction safety management in China," Safety Science, vol. 42, no. 7, pp. 569-586, 2004.

[32] CALOSHA, Pocket Guide for the Construction Industry, CALOSHA, Oakland, CA, USA, 2015, http://www.dir.ca.gov/ dosh/dosh_publications/constguideonline.pdf.

[33] M. Gunduz and H. Laitinen, "Observation based safety performance indexing method for construction industry-validation with SMEs," KSCE Journal of Civil Engineering, vol. 22, no. 2, pp. 440-446, 2018.

[34] H. Laitinen, M. Vuorinen, A. Simola, and E. Yrjänheikki, "Observation-based proactive OHS outcome indicators-validity of the elmeri+ method," Safety Science, vol. 54, pp. 69-79, 2013, 0925-7535.

[35] M. Gunduz and B. Ahsan, "Construction safety factors assessment through frequency adjusted importance index," International Journal of Industrial Ergonomics, vol. 64, pp. 155-162, 2018.

[36] D. Jescovitch, "Safety tips for weld prep in pipe fabrication," Welding Journal, vol. 94, no. 11, pp. 52-54, 2015.

[37] QCS, 2014, Qatar Construction Standards, Section 1, Part 10, pp 12-13.

[38] H. Laitinen, M. Marjamäki, and K. Päivärinta, "The validity of the TR safety observation method on building construction," Accident Analysis \& Prevention, vol. 31, no. 5, pp. 463-472, 1999.
[39] Y. Fang and Y. K. Cho, "Effectiveness analysis from a cognitive perspective for a real-time safety assistance system for mobile crane lifting operations," Journal of Construction Engineering and Management, vol. 143, no. 4, Article ID 05016025, 2017.

[40] G. Raviv, A. Shapira, and B. Fishbain, "AHP-based analysis of the risk potential of safety incidents: case study of cranes in the construction industry," Safety Science, vol. 91, pp. 298-309, 2017.

[41] T. S. Abdelhamid and J. G. Everett, "Identifying root causes of construction accidents," Journal of Construction Engineering and Management, ASCE, vol. 126, no. 1, pp. 52-60, 2000.

[42] I. Awolusi, E. Marks, and M. Hallowell, "Wearable technology for personalized construction safety monitoring and trending: review of applicable devices," Automation in Construction, vol. 85, pp. 96-106, 2018.

[43] C. Zhou and L. Y. Ding, "Safety barrier warning system for underground construction sites using internet-of-things technologies," Automation in Construction, vol. 83, pp. 372389, 2017.

[44] K. Kim, Y. Cho, and S. Zhang, "Integrating work sequences and temporary structures into safety planning: automated scaffolding-related safety hazard identification and prevention in BIM," Automation in Construction, vol. 70, pp. 128-142, 2016.

[45] J. C. Rubio-Romero, M. Carmen Rubio Gámez, and J. A. Carrillo-Castrillo, "Analysis of the safety conditions of scaffolding on construction sites," Safety Science, vol. 55, pp. 160-164, 2013.

[46] J. Bregulla, S. MacKay, and S. Matthews, "Fire safety on timber frame sites during construction," in Proceedings of the 11th World Conference on Timber Engineering, WCTE 2010, vol. 4, pp. 2805-2813, Trentino, Italy, June 2010. 